\title{
Pengendalian Banjir Batang Kuranji Menggunakan Program HEC-RAS
}

\author{
Suhendrik Hanwar \\ Arif Munandar** \\ *Politeknik Negeri Padang \\ ${ }^{*}$ Universitas Bung Hatta \\ E-mail : mr.suhendrik@gmail.com, semenarif@yahoo.com
}

\begin{abstract}
Abstrak
Batang Kuranji merupakan sungai yang memunyai luas DAS sebesar $187,50 \mathrm{~km}^{2}$. Banjir yang terjadi akibat luapan Batang Kuranji apabila itensitas hujan tinggi membuat kerugian bagi masyarakat disekitar aliran sungai. Pengendalian banjir direncanakan bertujuan untuk menaggulangi banjir sepanjang aliran batang kuranji. Dalam perhitungan Debit Banjir tahunan menggunakan metoda Melchior didapat $\mathrm{Q}_{10}$ adalah $730,48 \mathrm{~m} / \mathrm{dtk}$. Analisa banjir dilanjutkan menggunakan Program HEC-RAS 4.0 untuk mengetahui tinggi banjir dari luapan batang kuranji. Hasil analisa menggunakan HEC-RAS terhadap 9 buah cross memberikan gambaran hampir semua titik mengalami kondisi banjir (luapan), dan hanya beberapa titik saja yang tidak mengalami luapan. Hal ini disebabkan karena kontur daerah bagian hulu rendah. Hasil menggunakan HEC-RAS 4.0 didapat tinggi banjir setinggi 0,20 meter pada bagian hilir dan setinggi 1,40 meter pada bagian hulu. Perencanaan tanggul menjadi solusi sebagai penahan luapan air Batang Kuranji dengan dimensi tinggi 2,40 meter, lebar atas 1,00 meter dan lebar bawah 1,5 meter dengan kontrol stabilitas aman terhadap guling dan memenuhi safety factor. Solusi lain untuk perencanaan Normalisasi Sungai yaitu dengan analisa dimensi penampang sungai batang kuranji, didapat tinggi penampang sungai 3,25 meter, lebar atas 56,50 meter dan lebar bawah 50,00 meter.
\end{abstract}

Kata Kunci : Pengendalian Banjir,HEC-RAS 4.0,Tanggul

\section{PENDAHULUAN}

Sungai adalah aliran air yang besar dan memanjang yang mengalir secara terusmenerus dari hulu (sumber) menuju hilir (muara). Pada beberapa kasus, sebuah sungai secara sederhana mengalir meresap ke dalam tanah sebelum menemukan badan air lainnya.

Di Indonesia pada umumnya sungai merupakan sumber kehidupan bagi masyarakat setempat yang tinggal disekitar aliran sungai. Masyarakat setempat menggunakan sungai untuk kebutuhan sehari hari. Di daerah tertentu sungai menjadi mata pencaharian masyarakat setempat. Mereka menggunakan sungai untuk kegiata penambangan material galian $\mathrm{C}$ yang dapat menyebabkan terjadinya banjir.

Banjir merupakan fenomena alam yang biasa terjadi di suatu kawasan yang banyak dialiri oleh aliran sungai. Secara sederhana banjir dapat didefinisikan sebagai hadirnya air 
di suatu kawasan luas sehingga menututupi permukaan bumi kawasan tersebut.

Banjir sering mengakibatkan kerusakan fisik (seperti : merusak berbagai jenis struktur, termasuk jembatan, mobil, bangunan, sistem selokan bahwa tanah, jalan raya, dan kanal) dan kerusakan sekunder (seperti: persediaan air, penyaikit, pertanian, perpohonan dan transportasi).

Begitu juga dengan banjir yang terjadi di Kota Padang yang merupakan dampak dari factor alam karena intensitas hujan tinggi serta adanya aktifitas penambangan material galian C oleh masyarakat disekitar aliran Batang Kuranji. Penurunan dasar sungai akibat penambangan galian $\mathrm{C}$ yang tidak terkendali, kecepatan aliran yang masih tinggi dan cenderung menggerus tebing serta pada segmen hilir dengan permasalahan utama tanggul sungai yang rendah, tingkat sedimentasi yang tinggi mengakibatkan pendangkalan

bantaran sungai serta pencemaran yang menurunkan kualitas air. Sumber: (http://pu.go.id/berita/10072/Upaya-

\section{Pengendalian-Banjir-dan-Sedimen-Batang-}

Kuranji-Di-Kota-Padang).

Batang Kuranji merupakan sungai dengan panajang utama $18,60 \mathrm{Km}$. Batang Kuranji merupakan nama sungai yang membelah kota Padang di provinsi Sumatera Barat. Sungai ini berhulu pada sekitar Bukit Barisan antara kabupaten Solok dengan kota Padang, dan bermuara di Samudera Hindia. Tingginya curah hujan serta faktor manusia yang menyebabkan perubahan karakteristik terutama pada daerah hulu menjadi air dari aliran Batang Kuranji ini pada musim hujan sering meluap, dan menyebabkan banjir pada kawasan sekitarnya.

Berkaitan dengan banjir yang terjadi di Batang Kuranji tersebut, usaha untuk mengatasi banjir membutuhkan perencanaan yang mantap serta analisis yang benar dan akurat.

\section{METODOLOGI}

Metodologi yang digunakan dalam penulisan Tugas Akhir ini adalah studi literatut dan analisis data.

a. Literatur

b. Pengumpulan Data

c. Observasi/ Pengamatan Langsung

d. Konsultasi

Data yang diperlukan

\section{Data Curah Hujan Harian Maksimum}

Untuk normalisasi Batang Kuranji, data curah hujan yang diperoleh yaitu Stasiun Gunuang Nago, Stasiun Simpang Alai dan Stasiun Tabing dengan curah hujan 10 tahun. Untuk menentukan curah hujan digunakan metode rata-rata aljabar. Rumus yang di pakai yaitu :

Dimana :

$$
\begin{gathered}
P=\frac{P_{1}+P_{2}+P_{3}+\ldots+P_{n}}{n}=\frac{\sum_{i=1}^{n} P_{i}}{n} \\
\mathrm{P}=\text { Curah hujan daerah }(\mathrm{mm}) \\
\mathrm{n}=\text { Jumlah pos penakar hujan } \\
\mathrm{P}_{1}, \mathrm{P}_{2}, \ldots, \mathrm{P}_{\mathrm{n}}=\text { Curah hujan ditiap pos penakar } \\
\text { hujan (mm) }
\end{gathered}
$$

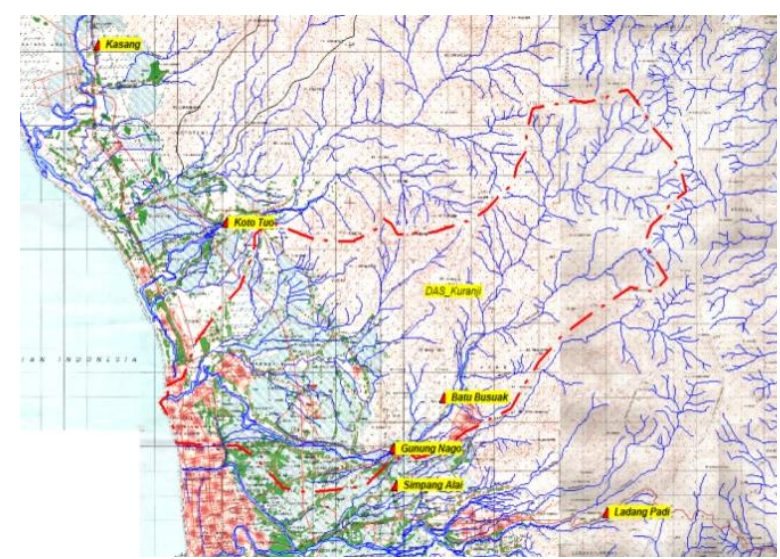


Gambar. Catchmen Area Batang Kuranji

\section{Analisa Curah Hujan Rencana}

Curah hujan rencana merupakan curah hujan terbesar tahunan dengan suatu kemungkinan periode ulang tertentu. Analisa curah hujan rencana bertujuan untuk menentukan periode ulang pada peristiwa hidrologis masa yang akan datang. Untuk perhitungan curah hujan rencana dilakukan dengan periode ulang 2 tahun, 5 tahun, 10 tahun, 25 tahun, 50 tahun, 100 tahun dengan menggunakan beberapa metode yaitu:

\section{a. Distribusi Normal}

Distrubusi normal adalah simetris terhadap sumbu vertical dan berbentuk lonceng yang juga disebut distribusi Gauss. Rumus yang di pakai yaitu:

$$
X_{T}=\bar{X}+K_{T} . S
$$

Dimana :

$\mathrm{X}_{\mathrm{T}}=$ curah hujan kala ulang $\mathrm{T}$-tahun

$\overline{\mathrm{X}}=$ nilai rata-rata hitung variat

$\mathrm{S}=$ standar Deviasi

$\mathrm{K}_{\mathrm{T}}=$ variable reduksi Gauss

\section{b. Distribusi Log Normal}

Distribusi log normal digunakan bila nilainilai dari variable random atau acak, tidak mengikuti distribusi normal tetapi nilai logaritmanya memenuhi distribusi normal. Adapun persamaan yang di gunakan yaitu:

$$
Y_{T}=\bar{Y}+K_{T} . S
$$

Dimana :
$Y_{T}=$ Curah hujan kala ulang $\mathrm{T}$ tahun $(\mathrm{mm})$

$\bar{Y}=$ Curah hujan maksimum rata-rata

$K_{T}=$ Variabel reduksi Gauss

$S$ = Standar deviasi

\section{c. Distribusi Gumbel}

Distribusi Gumbel banyak digunakan untuk analisis data maksimum, seperti untuk analisis frekuensi banjir. Rumus yang di pakai yaitu:

$$
X=\bar{X}+\frac{Y_{T}-Y_{n}}{S_{n}} S x
$$

Dimana :

$X=$ Curah hujan kala ulang $T$ tahun $(\mathrm{mm})$

\lrcorner$=$ Curah hujan maksimum rata-rata

$Y=$ Reduced variate (tabel hubungan dengan periode ulang, $t$ )

$\mathrm{Y}=$ Recuded mean (tabel hubungan dengan banyaknya data, $\mathrm{n}$ )

$S=$ Recuded standar deviasi (hubungan dengan banyak data,n)

$S=S t a n d a r$ deviasi

$\mathrm{n}=$ Banyak data tahun pengamatan

\section{d. Distribusi Log Person III}

Pearson telah mengembangkan banyak model matematika fungsi distribusi untuk membuat persamaan empiris dari suatu distribusi. Rumus yang di pakai yaitu:

$$
\log _{n}=Y_{r}+K_{T} \cdot S
$$

Dimana :

$R_{n}=$ Curah hujan kala ulang $\mathrm{T}$ tahun $(\mathrm{mm})$

$Y_{r}=$ Curah hujan maksimum rata-rata

$K_{T}=$ Variabel reduksi Gauss

$S=$ Standar deviasi

\section{Analisis Debit Banjir Rencana}


Analisis debit banjir yang dilakukan dengan periode ulang 2, 5, 10, 20, 50 dan 100 tahun. Proses perhitungan debit banjir dimulai dengan pengumpulan data hujan dan topografi. Setelah data curah hujan rata-rata dan curah hujan rencana didapat maka perhitungan debit banjir rencana dapat dilakukan dengan beberapa metode antara lain :

\section{a. Metoda Hasper}

Pada perhitungan debit banjir rencana metoda Hasper, tinggi hujan yang diperhitungkan adalah tinggi curah hujan pada titik pengamatan. Rumus yang di pakai yaitu:

$$
\mathrm{Q}_{\mathrm{T}}=\propto \beta \mathrm{fq}
$$

Dimana :

$Q=$ debit banjir rencana untuk periode

ulang $\mathrm{T}$ tahun $\left(\mathrm{m}^{3} / \mathrm{dtk}\right)$

$\alpha=$ Koefisien aliran

$\beta=$ Koefisien reduksi

$q=$ Hujan maksimum $\left(\mathrm{m}^{3} / \mathrm{dtk} / \mathrm{km}^{2}\right)$

$\mathrm{F}=$ Luas daerah pengaliran.

\section{b. Metode Weduwen}

Metode perhitungan banjir Der Weduwen diterbitkan pada tahun 1937. Metode tersebut cocok untuk daerah aliran sungai seluas 100 $\mathrm{km}^{2}$. Rumus yang di pakai yaitu:

$$
Q=\alpha \beta q_{n} f
$$

Dimana :

$\mathrm{Q}_{\mathrm{n}}=$ debit puncak banjir $\left(\mathrm{m}^{3} / \mathrm{dt}\right)$

$A=$ koefisien limpasan air hujan (runoff)

$\mathrm{B}=$ koefisien reduksi,

$\mathrm{q}_{\mathrm{n}}=$ debit persatuan luas $\left(\mathrm{m}^{3} / \mathrm{dt} . \mathrm{km}^{2}\right)$

$A=$ luas daerah aliran sungai $\left(\mathrm{km}^{2}\right)$

\section{c. Metode Rasional}

Metode Rasional banyak digunakan untuk memperkirakan debit puncak yang ditimbulkan oleh hujan daerah tangkapan DAS kecil. Pemakaian metode Rasional sangat sederhana. Beberapa parameter hidrologi yang diperhitungkan adalah intensitas hujan, durasi hujan, frekuensi hujan, luas DAS, absraksi (kehilangan air akibat evaporasi, intersepsi, infiltrasi, tampungan permukaan) dan konsentrasi aliran. Rumus yang di gunakan dalam metode ini yaitu:

$$
Q=0.278 \text { C.i.A }
$$

Dimana :

$\mathrm{Q}=$ debit puncak banjir $\left(\mathrm{m}^{3} / \mathrm{dt}\right)$

$\mathrm{I}=$ intensitas hujan $(\mathrm{mm} / \mathrm{jam})$

$A=$ luas daerah aliran sungai $\left(\mathrm{km}^{2}\right)$

$\mathrm{C}=$ Koefisien aliran

\section{d. Metode Melchior}

Metode Melchior metode perhitungan banjir rancangan untuk luas tangkapan hujan (catchment area) > $100 \mathrm{~km}^{2}$ (Sumber : Balitbang, 2002, NSPM KIMPRASWIL Pedoman dan Petunjuk teknik dan manual Irigasi (Standar Perencanaan Irigasi) Edisi ke1, Jakart). Rumus yang di pakai yaitu:

$$
\mathrm{Q}_{\text {maks }}=\alpha \cdot \mathrm{I} \cdot \mathrm{A} \cdot \frac{\mathrm{r}}{200}
$$

Dimana :

$$
\begin{aligned}
& Q_{\text {maks }}=\text { Debit maksimum }\left(\mathrm{m}^{3} / \mathrm{dt}\right) \\
& \alpha \quad=\text { Koefisien pengaliran (Table 2.1.) } \\
& \beta \quad=\text { Koefisien reduksi, } \\
& \mathrm{I} \quad=\text { Intensitas Hujan }\left(\mathrm{m}^{3} / \mathrm{dt} / \mathrm{km}^{2}\right) \\
& A \quad=\text { Luas daerah aliran sungai }\left(\mathrm{km}^{2}\right)
\end{aligned}
$$

\section{Normalisasi Sungai}

Mengecilnya kapasitas sungai dikarenakan terjadinya pendangkalan akibat penumpukan sedimentasi dan penyempitan badan sungai, baik karena faktor alam maupun ulah manusia itu sendiri merupakan penyebab terjadinya banjir. Salah satu yang sering menjadi penyebab banjir adalah menjamurnya rumah di sekitar aliran sungai serta adanya aktifitas penambangan material galian C. Agar air tidak 
meluap yang menyebabkan banjir, normalisasi sungai menjadi salah satu solusi untuk menanggulangi bencana yang menjadi salah satu penyebab banjir di Kota Padang, khususnya masyarkat di sekitar aliran sungai kuranji.

Normalisasi sungai adalah suatu metode yang digunakan untuk menyediakan alur sungai dengan kapasistas mencukupi untuk menyalurkan air, terutama air yang berlebih saat curah hujan tinggi. Tujuan normalisasi sungai antara lain untuk keperluan navigasi, melindungi tebing sungai karena erosi (kikisan), atau untuk memperluas profil sungai guna menampung banjir-banjir yang terjadi.

Normalisasi sungai mencakup pengerasan dinding sungai, pembangunan sudetan, pembuatan tanggul dan juga pengerukan. Pengerasan atau penguatan tebing sungai dilakukan dengan pembetonan dinding atau dengan pemasangan batukali, sudetan dilakukan dengan membuat sungai baru yang lurus dengan lintasan terpendek. Sedangkan pembuatan tanggul dilakukan dengan timbunan tanah atau dengan dinding beton maupun dengan pasangan batu kali yang dipasang memanjang di lokasi-lokasi bergeografi rendah yang rawan banjir.

\section{a. Saluran Banjir}

Apabila debit banjir rencana terlalu besar dan tidak memungkinkan peningkatan kapasitas tampung sungai di atas kapasitasnya yang sudah ada, maka penambahan kapasitasnya dapat dilakukan dengan pembuatan saluran baru langsung kelau, danau atau sungai lain yang disebut saluran banjir. Saluran banjir adalah saluran baru yang dibuat untuk mengalirkan sebagian atau bahkan seluruh debit banjir. Saluran ini dibuat dalam berbagai kondisi, tetapi tujuan utamanya biasanya adalah untuk menghindarkan pekerjaan sungai didaerah pemukiman yang padat atau untuk memperpendek salah satu ruas sungai.

\section{b. Sudetan}

Pada ruas sungai yang belokanbelokannya sangat tajam atau meandernya sangat kritis, maka tanggul yang akan dibangun biasanya akan menjadi lebih panjang. Selain itu pada ruas sungai yang demikian, gerusan pada belokan luar sangat meningkat dan terjadi kerusakan tebing sungai yang akhirnya akan mengancam kaki tanggul tersebut. Jadi alur sungai menjadi lebih panjang dan dapat menggangu kelancaran aliran banjir. Guna mengurangi keadaan yang kurang menguntungkan tersebut, maka pada ruas sungai tersebut perlu dipertimbangkan pembuatan alur baru, agar pada ruas tersebut alur sungai mendekati garis lurus dan lebih pendek.

Saluran semacam itu disebut dengan sudetan. Sudetan ini akan menurunkan muka air disebelah hulunya tetapi dibagian hilir akan naik sedikit. Dengan demikian dasar sungai disebelah hulu sudetan tergerus dan pengendapan terjadi didasar sungai disebelah hilirnya..

\section{c. Pengendalian Sedimen}

Sungai mengalirkan air bersama sedimen yang terdapat dalam aliran air tersebut. Dibagian hulu kandungan sedimennya tinggi, tetapi sesampainya dibagian hilir terjadilah pengendapan membentuk endapan deluvial atau aluvial. Adapun penyebab alamiah perubahan resmi dan dasar sungai adalah adanya sedimen yang terkandung didalam 
aliran air yang masuk dari daerah pegunungan.

Alur sungai yang stabil dapat dicapai apabila dapat diukur kapasitas sedimen yang masuk kedalam alur sungai seimbang dengan kapasitas yang ke luar dimuara sungai. Walaupun demikian sebagaimana telah diuraikan sebelumnya, perubahan resim sungai akan senantiasa terjadi, apabila pada sungai tersebut dilaksanakan pekerjaan sungai yang besar.

\section{Program HEC - RAS.}

Elevasi muka air pada alur sungai perlu dianalisis untuk mengetahui pada bagian manakah terjadi luapan pada alur sungai, sehingga dapat ditentukan solusi untuk penanganan agar luapan sungai kuranji dapat teratasi. Solusi untuk mengatasi luapan air sungai yang mengakibatkan banjir diantaranya analisa dimensi sungai serta pembuatan tanggul sebagai penahan luapan air sungai.

Dalam menganalisis kondisi sungai tersebut dapat digunakan program HEC-RAS 4.0 yang dikeluarkan oleh U.S Army Corps of Engineers. Program HEC-RAS sendiri dikembangkan oleh The Hydrologic Engineer Centre (HEC) yang merupakan bagian dari U.S Army Corps of Engineers.

\section{a. Analisa profil aliran menggunakan Program HEC-RAS}

HEC-RAS adalah system software terintegrasi, yang didesain untuk digunakan secara interaktif pada kondisi tugas yang beraneka ragam. Sistem ini terdiri dari interface grafik pengguna, komponen analisa hidrolika terpisah, kemampuan manajemen dan tampungan data, fasilitas pelaporan dan grafik.
Sistem HEC-RAS pada akhirnya akan memuat tiga komponen analisa hidrolika satu dimensi untuk:

1. Perhitungan profil muka air aliran seragam (steady flow),

2. Simulasi aliran tidak seragam,

3. Perhitungan transport sedimen dengan batas yang bisa dipindahkan.

Ketiga komponen tersebut akan menggunakan representasi data geometri serta perhitungan hidrolika dan geometri seperti pada umumnya.

Versi terakhir dari HEC-RAS yaitu HECRAS 4.0 mendukung perhitungan profil muka air aliran tunak dan tidak tunak.

Terdapat lima langkah penting dalam membuat model hidrolika dengan menggunakan HEC-RAS:

1. Memulai proyek baru

2. Memasukkan data geometri

3. Memasukkan data aliran dan kondisi batas

4. Melakukan perhitungan hidrolika

5. Menampilkan dan mencetak hasil

\section{HASIL PENGOLAHAN DATA.}

Berikut Hasil rekapitulasi perhitungan curah hujan rencana dari keempat metoda :

\begin{tabular}{|c|c|c|c|r|r|r|}
\hline \multirow{2}{*}{ Metode } & \multicolumn{7}{|c|}{ Periode Ulang } \\
\cline { 2 - 7 } & $\begin{array}{c}\mathbf{2} \\
\text { tahun }\end{array}$ & $\begin{array}{c}\mathbf{5} \\
\text { tahun }\end{array}$ & $\begin{array}{c}\mathbf{1 0} \\
\text { tahun }\end{array}$ & $\begin{array}{c}\mathbf{2 0} \\
\text { tahun }\end{array}$ & $\begin{array}{c}\mathbf{5 0} \\
\text { tahun }\end{array}$ & $\begin{array}{c}100 \\
\text { tahun }\end{array}$ \\
\hline Normal & 165.2 & 202.28 & 221.7 & 237.6 & 255.7 & 268.03 \\
\hline $\begin{array}{c}\text { Log } \\
\text { Normal }\end{array}$ & 160.7 & 196.8 & 218.8 & 238.8 & 263.6 & 282.49 \\
\hline Gumbel & 159.2 & 211.9 & 246,8 & 280,3 & 323.5 & 355.98 \\
\hline
\end{tabular}




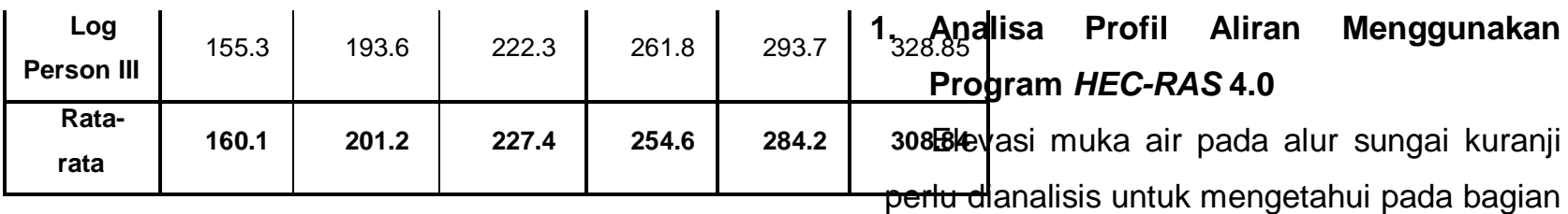

Debit banjir yang dipakai adalah hasil perhitungan dari metode Melchior karena luas DAS (catchment area) $>100 \mathrm{~km}^{2}$, sedangkan dari metode yang lain hanya sebagai perbandingan dari metode yang ada. Maka didapatkan:

$$
\mathrm{Q}_{2 \text { normal }}=\mathbf{5 1 4 , 3 5} \mathrm{m}^{3} / \text { detik }
$$

$Q_{10 \text { banjir desain }=730,48 \mathrm{~m}^{3} / \text { detik }}$

Berikut adalah rekapitulasi dari keempat metode Debit Banjir :

\begin{tabular}{|c|c|c|c|c|}
\hline $\begin{array}{c}\mathbf{T} \\
\text { (Tahun) }\end{array}$ & $\begin{array}{c}\text { Hasper } \\
\left(\mathbf{m}^{3} / \mathbf{d t}\right)\end{array}$ & $\begin{array}{c}\text { Wedu } \\
\text { wen } \\
\left(\mathbf{m}^{3} / \mathbf{d t}\right)\end{array}$ & $\begin{array}{c}\text { Rasion } \\
\text { al } \\
\left(\mathbf{m}^{3} / \mathbf{d t}\right)\end{array}$ & $\begin{array}{c}\text { Melch } \\
\text { ior } \\
\left(\mathbf{m}^{3} / \mathbf{d t}\right. \\
)\end{array}$ \\
\hline 2 & 1309. & 503.1 & 809,7 & $\mathbf{5 1 4}$ \\
& 20 & 5 & 1 & $\mathbf{3 5}$ \\
5 & 1644. & 632.2 & 1017, & $\mathbf{6 4 6}$, \\
& 67 & 0 & 69 & $\mathbf{2 5}$ \\
\multirow{2}{*}{$\mathbf{1 0}$} & $\mathbf{1 8 5 9 .}$ & $\mathbf{7 1 4 . 6}$ & $\mathbf{1 1 5 0 ,}$ & $\mathbf{7 3 0}$ \\
& $\mathbf{2 4}$ & $\mathbf{0}$ & $\mathbf{2 9}$ & $\mathbf{4 8}$ \\
& 2081. & 800.1 & 1287, & $\mathbf{8 1 7}$ \\
& 44 & 9 & 90 & $\mathbf{9 7}$ \\
50 & 2323. & 893.0 & 1437, & $\mathbf{9 1 2}$ \\
& 27 & 5 & 40 & $\mathbf{9 0}$ \\
100 & 2525. & 970.6 & 1562, & $\mathbf{9 9 2}$ \\
& 83 & 4 & 18 & $\mathbf{2 1}$ \\
\hline
\end{tabular}
manakah terjadi luapan pada alur sungai kuranji, sehingga dapat ditentukan solusi yang digunakan untuk mengatasi masalah banjir disepanjang aliran sungai kuranji. Data-data yang diperlukan sebelum menjalankan program HEC-RAS adalah sebagai berikut:

a. Data debit banjir $Q_{10}$

$$
=730,48 \mathrm{~m}^{3} / \text { detik }
$$

b. Data Geometri

$=$ Data kontur penampang sungai

c. Kemiringan Sungai $(\mathrm{H})$

$=$ Elv. Hulu - Elv. Hilir

$=319.04-315.32=3.72$

$L_{1}=0.9 \times 19.80=17.82$

$S=\frac{3.72}{17.82}=0.208$

$S^{1}=20 \% \times 0.208=0.041$

Adapun hasil dari running menggunakan Program HEC-RAS :

\section{a. STA B41}

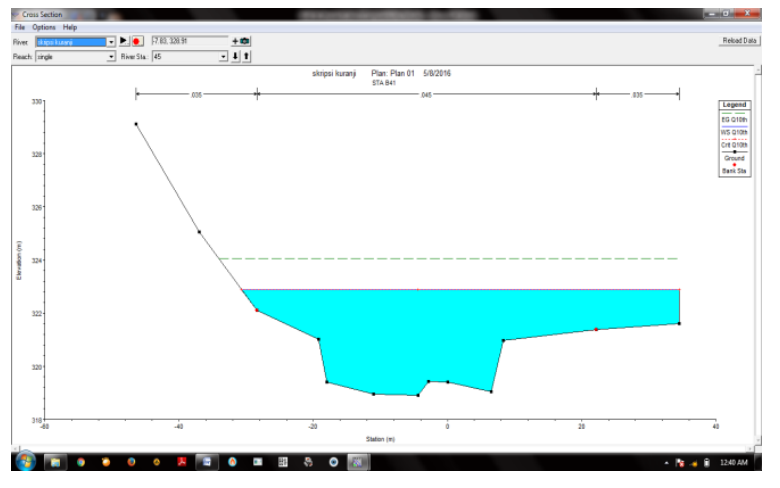

Terlihat hasil runnning pada cros section STA B41 terjadi luapan air sungai disebelah kanan setinggi 1.4 meter dikarenakan kontur daerah sebelah kanan rendah (Low Land). 
b. STA B40

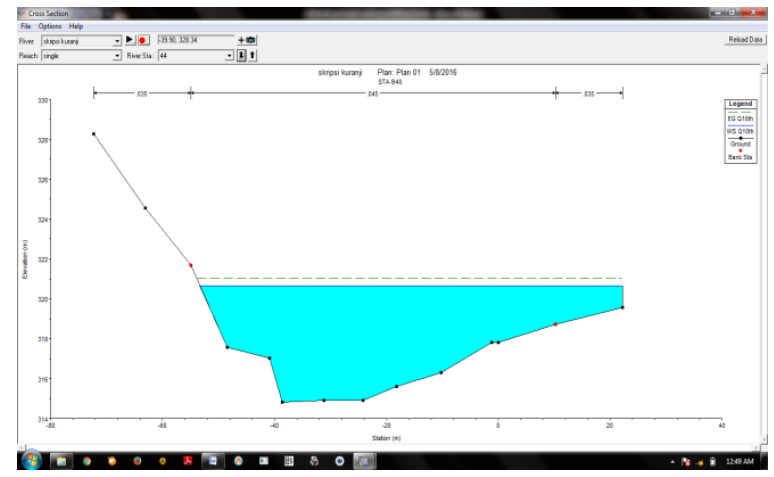

Terlihat hasil runnning pada cros section STA B40 terjadi luapan air sungai disebelah kanan setinggi 1.2 meter.

c. STA B39B

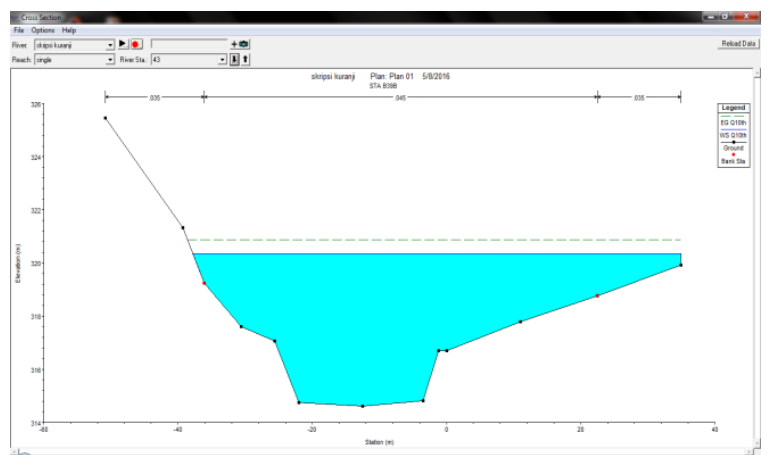

Terlihat hasil runnning pada cros section STA B39B terjadi luapan air sungai disebelah kanan setinggi 0.6 meter.

d. STA B39A

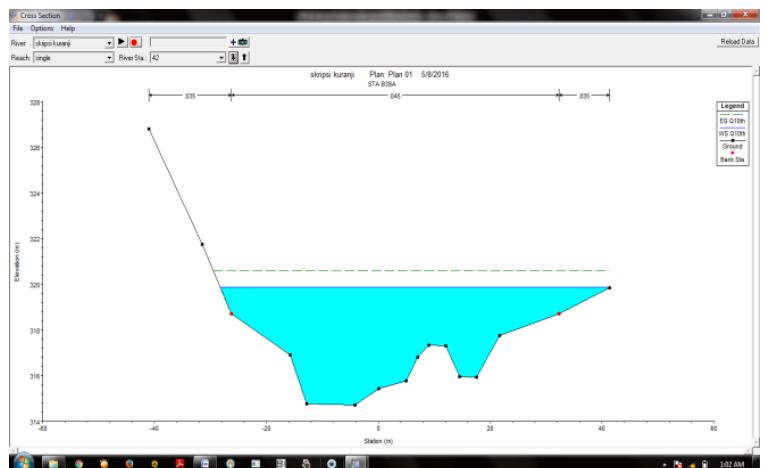

Terlihat hasil runnning pada cros section STA B39A tidak terjadi luapan air sungai.

e. STA B39

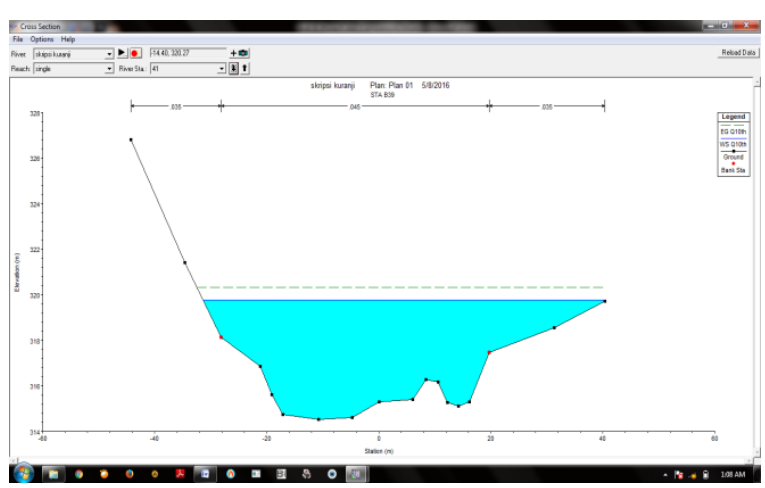

Terlihat hasil runnning pada cros section STA B39 tidak terjadi luapan air sungai.

\section{f. STA B38A}

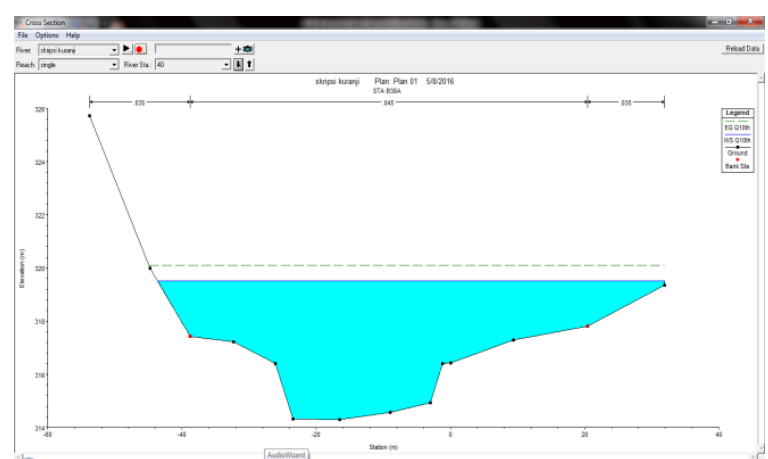

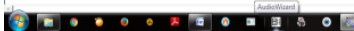

Terlihat hasil runnning pada cros section STA B38A terjadi luapan air sungai disebelah kanan setinggi 0.2 meter.

g. STA HP

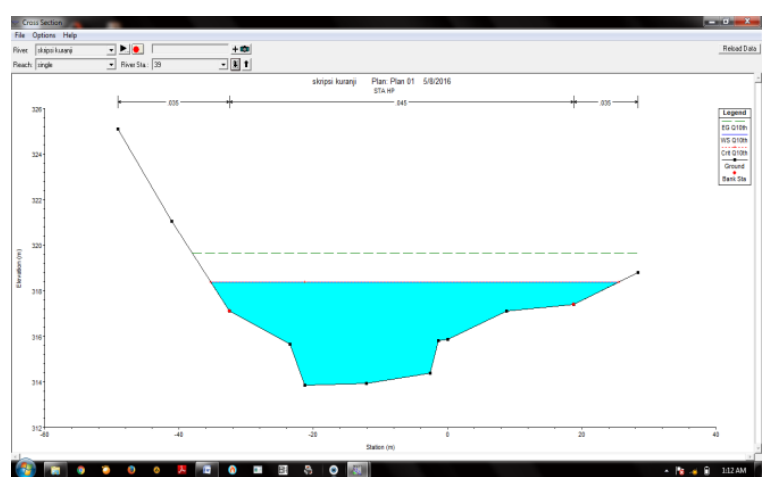


Terlihat hasil runnning pada cros section STA HP tidak terjadi luapan air sungai.

\section{h. STA B38}

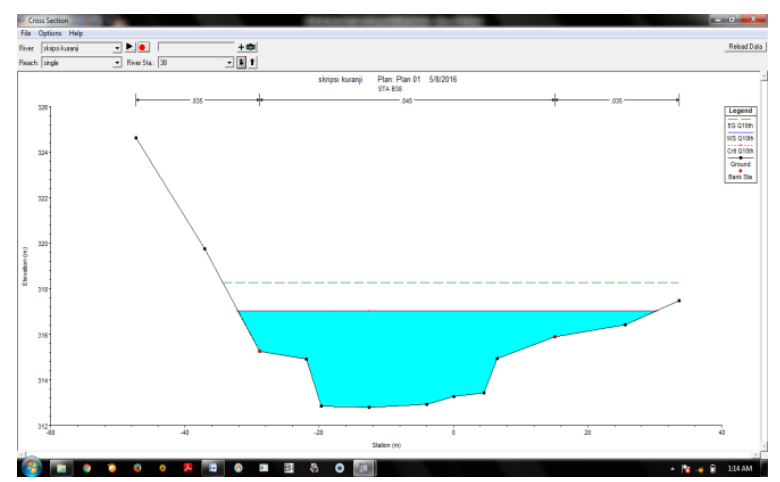

Terlihat hasil runnning pada cros section STA B38 tidak terjadi luapan air sungai disisi kiri maupun kanan.

\section{i. $\quad$ STA B37}

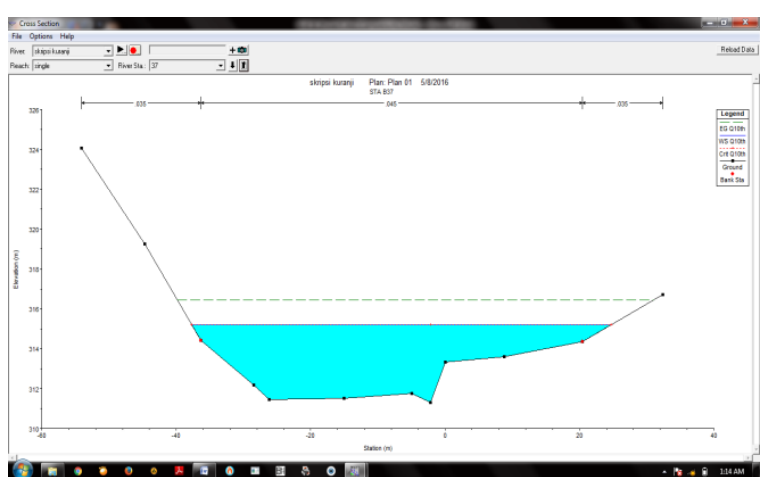

Terlihat hasil runnning pada cros section STA B37 tidak terjadi luapan air sungai disisi kiri maupun kanan.

Hasil running dengan tampilan Cross Section :

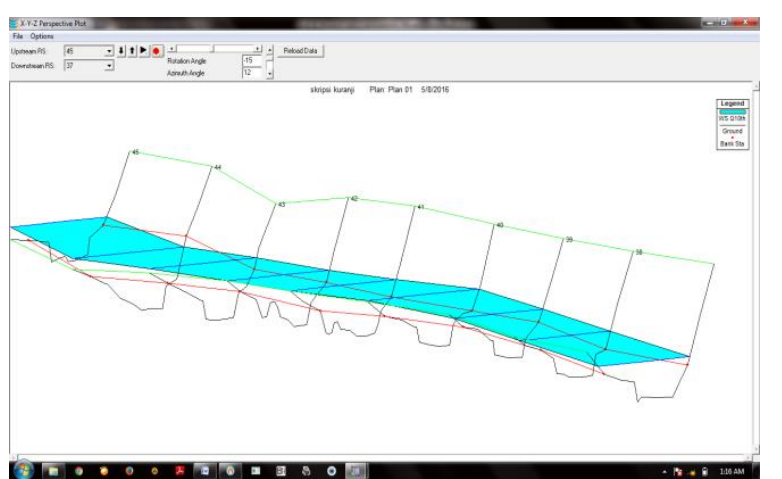

\section{Perhitungan Tinggi Banjir}

Dalam menganalisis tinggi banjir menggunakan program HEC-RAS, kita juga dapat menganalisis tinggi banjir menggunakan perhitungan dimensi penampang Batang Kuranji menggunakan data debit rencana periode ulang 10 tahun sebesar 730,48 $\mathrm{m}^{3} /$ detik. Dimensi Batang Kuranji dicoba direncanakan dengan menggunakan model saluran trapesium Rumus yang di pakai yaitu :

$$
\begin{aligned}
\mathrm{Q} & =\mathrm{A} \cdot \mathrm{V} \\
\mathrm{A} & =(\mathrm{b}+\mathrm{m} \cdot \mathrm{h}) \mathrm{h} \\
\mathrm{P} & =\mathrm{b}+2^{m^{2}+1} \cdot \mathrm{h} \\
\mathrm{R} & =\mathrm{A} / \mathrm{P} \\
\mathrm{V} & =1 / \mathrm{n} \cdot \mathrm{R}^{2 / 3} \cdot \mathrm{I}^{1 / 2}
\end{aligned}
$$

Dimana :

$\mathrm{Q}=$ Debit $\left(\mathrm{m}^{3} /\right.$ detik)

$\mathrm{V}=$ Kecepatan aliran rata-rata (m/detik)

$\mathrm{n}$ = Koefisien kekasaran manning

$\mathrm{R}=$ Jari-jari hidrolis $(\mathrm{m})$

$P=$ Keliling basah $(m)$

$\mathrm{m}=$ Talud

$A=$ Luas keliling basah $\left(\mathrm{m}^{2}\right)$

$\mathrm{I}=$ Kemiringan saluran

\section{Dimensi Penampang Batang Kuranji}

Data Desain : $Q_{2}$ normal design

$=514,35 \mathrm{~m}^{3} /$ detik

$\mathrm{Q}_{10}$ banjir design $=730,48 \mathrm{~m}^{3} /$ detik

I dasar sungai $=0,041$

Penampang desain berbentuk trapesium tunggal dengan talud 1: 1 Direncanakan :

Lebar B1 $=50 \mathrm{~m}$

Koef. Manning $(n)=0,035$

a. Mencari tinggi $h_{1}$ 
Tinggi $h_{1}$ didapat dengan menggunakan cara coba-coba : 1,40 meter.

Didapat tinggi $h_{1}=1.40 \mathrm{~m}$

- Luas Penampang basah

$$
\begin{aligned}
A & =(50+h) \times H \\
& =71.96 \mathrm{M}^{2}
\end{aligned}
$$

- Keliling Penampang basah

$\mathrm{P}=\mathbf{b}+\mathbf{2}^{\sqrt{m^{2}+1}} \cdot \mathbf{h}$

$=53.09 \mathrm{M}^{2}$

- Jari-jari Hidrolik

- $\mathbf{R}=\frac{A}{P}=\frac{71.96}{53.09}=1.355$

- Kecepatan rata-rata

$\mathrm{V}=\frac{1}{\mathrm{n}} \times \mathrm{R}^{\frac{2}{3}} \mathrm{x} \mathrm{I}^{\frac{1}{2}}$

$=7.086 \mathrm{~m} /$ detik

- Debit

$Q_{\text {Disain }}=A \times V$

$$
\begin{aligned}
& =71.96 \times 7.086 \\
& =509.879 \mathrm{~m}^{3} / \text { detik. }
\end{aligned}
$$

Tinggi Penampang untuk $Q_{\text {normal }}=509.879$

$\mathrm{m}^{3} / \mathrm{dt}$ adalah $\left(\mathrm{h}_{1}\right)=1.40 \mathrm{~m}$.

b. Mencari tinggi $h_{2}$

Lebar B2 $=\mathrm{B} 1+2 \cdot \mathrm{m} \cdot \mathrm{h}_{1}$

$=52.8 \mathrm{~m}$

Debit h2 = Debit Banjir - Debit normal

$=216.13 \mathrm{~m}^{3} /$ detik

Tinggi $h_{2}$ didapat dengan menggunakan cara coba-coba :

Didapat tinggi $h_{2}=0.85 \mathrm{~m}$

$A=\left(b 2+m . h_{2}\right) h_{2}$

$=43.223 \mathrm{~m}^{2}$

$\mathrm{P}=\mathrm{b} 2+2 \sqrt{m^{2}+} . \mathrm{h}_{2}$

$=55.52 \mathrm{~m}$

$R=A / P$

$=0.779 \mathrm{~m}$
$\mathrm{V}=1 / \mathrm{n} \cdot \mathrm{R}^{2 / 3} \cdot \mathrm{I}^{1 / 2}$

$=4.896 \mathrm{~m} / \mathrm{deti \textrm {K }}$

$\mathrm{Q}=\mathrm{A} \cdot \mathrm{V}$

$=211.612 \mathrm{~m}^{3} /$ detik

Tinggi penampang untuk $Q_{2 \text { (desain) }}=211.612$

$\mathrm{m}^{3} / \mathrm{dt}$ adalah $\left(\mathrm{h}_{2}\right)=0,85 \mathrm{~m}$

Tinggi tanggul jagaan 1 meter.

Jadi tinggi keseluruhan tanggul $(H)$ :

$\mathrm{H}_{\text {total }}=\mathrm{h} 1+\mathrm{h}_{2}+\mathrm{F}$

$=1.40+0.85+1.00$

$=3.25 \mathrm{~m}$

Dari perhitungan di atas maka dapat di gambarkan bentuk penampang yang di rencanakan adalah sebagai berikut:

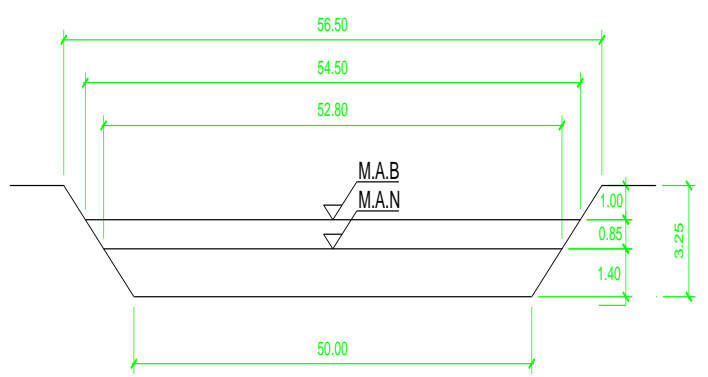

\section{Perencanaan Tanggul dan Kontrol Stabilitas Tanggul}

Dari hasil running analisa profil aliran dengan menggunakan program HEC-RAS 4.0 maka didapatkan tinggi luapan air sungai kuranji yang menyebabkan banjir setinggi 0,2 sampai 1,40 meter. Dalam mengatasi masalah banjir sungai kuranji penulis memilih perencanaan tanggul sebagai solusi agar luapan banjir tidak lagi merugikan masyarakat sekitar aliran sungai kuranji.

\section{a. Perencanaan Typical Tanggul}

Adapun dasar perencanaan tanggul sebagai berikut :

1. Debit rencana: Q 10 th adalah 730,48 $\mathrm{m}^{3} /$ detik 
2. Bahan : Pasangan batu

3. Ppas. batu $: 2,2$ ton $/ \mathrm{m}^{3}$

4. Pair $: 1,0$ ton $/ \mathrm{m}^{3}$

5. Tinggi tanggul $: 1,40$ meter

6. Tinggi jagaan $: 1,00$ meter

7. Total Tinggi tanggul: 2.40 meter.

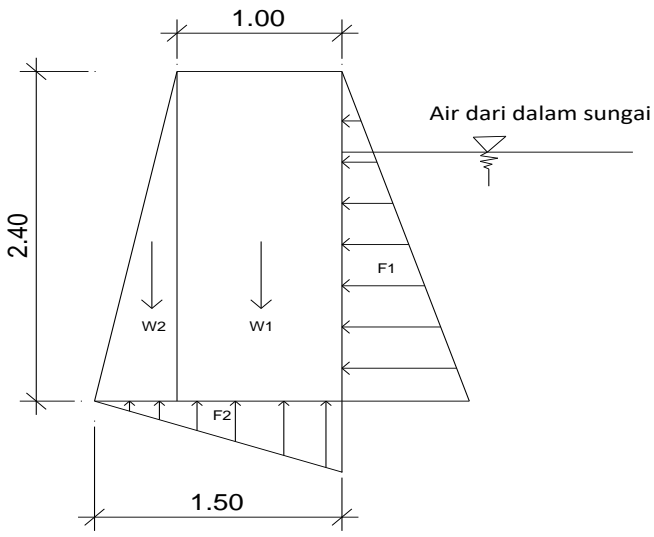

b. Analisa Stabilitas Tanggul

\section{Berat Sendiri Tanggul}

Langkah perhitungan segmen $\mathrm{W}_{1}$ tinjauan lebar $1 \mathrm{~m}$ :

1. Data

$\mathrm{Y}_{\mathrm{b}}=$ Berat isi Pasangan Batu Kali $=2,2$ $\mathrm{t} / \mathrm{m}^{3}$
A = Luas penampang Tanggul
$\mathrm{L}_{x} \quad=$ Lengan momen arah horizontal

2. Hitung berat struktur

$$
\begin{aligned}
& W=A \times \gamma_{b} \\
& W 1=(2.4 \times 1) \times 2,2=5.28 t
\end{aligned}
$$

3. Hitung Momen

$$
\begin{aligned}
& L_{x}=\left(\left(\frac{1}{2} x 1\right)+0.5\right)=1.00 m \\
& M=W \times L_{x} \\
& M=5.28 \times 1.00=5.28 \mathrm{t} . \mathrm{m}
\end{aligned}
$$

\section{Tekanan Air}

Langkah perhitungan segmen $\mathrm{F} 1$ tinjauan lebar $1 \mathrm{~m}$

1. Data

$\gamma_{\mathrm{w}}=$ Berat isi air $=1 \mathrm{t} / \mathrm{m}^{3}$

$\mathrm{L}_{x} \quad=$ Lengan momen arah horizontal

$L_{y} \quad=$ Lengan momen arah vertikal

2. Hitung tekanan air normal segmen $F_{1}$

$$
\begin{aligned}
& \mathrm{P}_{\mathrm{h}}=1 / 2 \times \gamma_{\mathrm{w}} \mathrm{xH}^{2} \\
& \mathrm{P}_{\mathrm{h}}=1 / 2 \times 1 \times 2.4^{2}=2.88 \mathrm{t}
\end{aligned}
$$

3. Hitung Momen segmen $F_{1}$

$$
\begin{aligned}
& \mathrm{L}_{\mathrm{x}}=\frac{1}{3} \times 2.4=0.8 \mathrm{~m} \\
& \mathrm{M}=\mathrm{P}_{\mathrm{h}} \times \mathrm{L}_{\mathrm{x}} \\
& \mathrm{M}=2.88 \times 0.8=2.304 \mathrm{t} . \mathrm{m}
\end{aligned}
$$

4. PENUTUP.

1. Kesimpulan

Kesimpulan dari uraian diatas adalah sebagai berikut:

1. Hasil dari analisa curah hujan adalah sebagai berikut : Debit yang diambil adalah debit dengan periode ulang 10 tahun, yaitu sebesar $730,48 \mathrm{~m}^{3} / \mathrm{d}$

2. Analisa profil aliran batang kuranji menggunakan program HEC-RAS untuk mengetahui tinggi banjir pada periode ulang Q10 th. 
3. Hasil running dari program HEC-RAS didapatkan tinggi banjir maksimal 1.40 meter.

4. Solusi dari penanganan banjir pada batang kuranji adalah membangun tanggul dari pasangan batu

5. Gambar typical tanggul sebagai penahan banjir.

6. Kontrol stabilitas tanggul terhadap guling :

$$
\mathrm{fg}=\frac{7.73}{2.88}=2,68>1,5
$$

\section{DAFTAR PUSTAKA.}

Triatmodjo, Bambang, 2008, Hidrologi Terapan, Beta Offset, Yogyakarta.

Triatmodjo, Bambang, 2003, Hidraulika II, Yogyakarta.

C.D. Sumarto, 1999, Hidrologi Teknik Edisi ke2, Erlangga, Jakarta.

Balitbang, 2002, NSPM KIMPRASWIL

Pedoman dan Petunjuk teknik dan manual Irigasi (Standar Perencanaan Irigasi) Edisi ke-1, Jakarta.

Kamiana, I Made, 2012, Teknik Perhitungan Debit Rencana Bangunan Air, Garaha IImu, Yogyakarta.

Utama, Lusi, 2013, Hidrologi Teknik, Bung Hatta University Press, Padang

Oehadijoko, 1993, Dasar-Dasar Teknik Sungai, Jakarta.

Sosrodarsono, Suyono, 2003, Hidrologi Untuk Pengairan, PT Pradnya Paramita, Jakarta.

Sosrodarsono, Suyono, 2008, Perbaikan dan Pengaturan Sungai, PT Pradnya Paramita, Jakarta.

Sri Harto Br. 1993, Analisis Hidrologi, PT Gramedia Pustaka Utama, Jakarta.
Suripin, 2003, Sistem Drainase Perkotaan yang

Berkelanjutan,

Andi 
